\title{
Constitucionalismo abusivo en el Perú: Un análisis a la vacancia presidencial por incapacidad moral y los hechos posteriores al 9 de noviembre de $\left.\left.\left.2020^{(*)}\right)^{(* *}\right)^{\left(*^{* *}\right)}()^{(* * *}\right)$
}

\author{
Abusive Constitutionalism in Peru: An analysis of presidential vacancy for \\ moral incapacity and the events after November 9, 2020
}

\author{
Massiel Jhadira Rodríguez Mendoza ${ }^{(+*+*+*)}$ \\ Pontificia Universidad Católica del Perú (Lima, Perú)
}

\begin{abstract}
Resumen: El presente artículo propone una vista distinta de los hechos ocurridos el 9 de noviembre de 2020 y posteriores en el Perú, a raíz de la vacancia presidencial de Martín Vizcarra por la causal de incapacidad moral. La mirada para analizar estos sucesos se centran en la hipótesis de que el Perú presenció un Constitucionalismo abusivo por parte del Congreso de la República, hipótesis que se busca probar a lo largo del trabajo. En primer lugar, la investigación detalla y explica las concepciones iniciales que tiene el Constitucionalismo abusivo y cómo la doctrina ha ido delimitando el concepto. En segundo lugar, se proponen nuevas formas de manifestación que puede tener el Constitucionalismo abusivo más allá de su definición inicial, de tal manera que pueda incluir otros supuestos en los que se esté socavando la democracia mediante mecanismos aparentemente constitucionales. En tercer lugar, se realiza un estudio crítico al sistema de gobierno peruano y las instituciones constitucionales que ha adoptado en su organización, lo que permite identificar los puntos débiles de su estructura política y cómo el Constitucionalismo abusivo puede manifestarse. En cuarto lugar, se analiza la figura de la vacancia por incapacidad moral y cuáles podrían ser sus posibles delimitaciones. Por último, se realiza el análisis final a los hechos ocurridos el 9 de noviembre de 2020 y se determina la presencia de un Constitucionalismo abusivo en la actuación del Congreso.
\end{abstract}

Palabras clave: Derecho Constitucional - Constitucionalismo abusivo - Vacancia Presidencialismo Latinoamericano - Incapacidad moral - Perú - Martín Vizcarra - 9 de noviembre de 2020

$\left(^{*}\right) \quad$ Nota del Editor: Este artículo fue recibido el 12 de marzo de 2021 y su publicación fue aprobada el 6 de mayo de 2021.

$\left({ }^{* *}\right) \quad$ El presente artículo fue realizado bajo la asesoría del Mg. Heber Joel Campos Bernal, quien es profesor ordinario de la Facultad de Derecho de la Pontificia Universidad Católica del Perú (PUCP). Sin sus aportes, este artículo no hubiese sido posible.

$\left(^{* * *}\right)$ La autora desea conmemorar a Inti Sotelo y Brian Pintado, víctimas de la violencia policial durante las protestas en contra de las acciones inconstitucionales del Congreso. A ellos, gracias por defender la democracia. Siempre en nuestra memoria.

$\left({ }^{* * * *}\right)$ La autora desea brindar un agradecimiento a sus padres, Grover Rodríguez y Judith Mendoza, por su amor y apoyo incondicional en cada paso que da. A sus hermanos, Dan Rodríguez y Darlene Rodríguez, por ser quienes se alegran con ella en cada logro. A sus abuelos, Ananías Rodríguez, Margarita Espinoza, Eugenio Mendoza y Cristina Castillo, por siempre tenerla presente en sus pensamientos y oraciones. Pero, sobre todo, un agradecimiento especial a Dios, quien puso el querer como el hacer, por su buena voluntad.

${ }^{(* * * *)}$ Alumna de séptimo ciclo de la Facultad de Derecho de la Pontifica Universidad Católica del Perú (PUCP). Miembro ordinaria de la Asociación Civil IUS ET VERITAS. Miembro de la Red Nacional de Asociaciones Jurídicas del Perú (REDNAJUR) en representación de la asociación antes mencionada. Ha sido Editora en Jefe de la Revista Jurídica IUS ET VERITAS. Practicante Preprofesional en el Área Procesal del Estudio Payet, Rey, Cauvi \& Pérez Abogados. Asistenta de Cátedra en el curso de Psicología y Derecho de la PUCP. Interés en temas de Derecho Constitucional, Derecho Procesal y Derechos Fundamentales. ORCID: https://orcid.org/00000003-1624-2541. Correo electrónico: massiel.rodriguez@pucp.edu.pe. 


\begin{abstract}
This article proposes a different view of the events that occurred on November 9, 2020, and later in Peru: the presidential vacancy of Martín Vizcarra because of the cause of moral incapacity and Manuel Merino's assumption of the government. The view to analyzing the events is the hypothesis that Peru has rated Abusive Constitutionalism by the Congress of the Republic, a hypothesis that is sought to prove throughout the article. First, the research details and explains the initial conceptions of Abusive Constitutionalism and how the doctrine has been delimiting the concept. Second, new forms of manifestation are proposed that abusive Constitutionalism may have beyond its initial definition so that it can include other situations in which democracy is being undermined through seemingly constitutional mechanisms. Third, a critical study is carried out on the Peruvian system and the constitutional institutions it has adopted in its organization, which allows identifying the weaknesses of its political structure and how Abusive Constitutionalism can manifest itself. Fourthly, the figure of the vacancy for moral incapacity is analyzed and what its possible delimitations might be. Finally, the final analysis is carried out to the events that occurred on November 9, 2020, and the presence of Abusive Constitutionalism in the decision of the Congress.
\end{abstract}

Key words: Constitutional Law - Abusive Constitutionalism Vacancy - Latin American Presidentialism - Moral incapacity - Peru - Martín Vizcarra - November 9, 2020

\section{Ideas preliminares}

Hemos observado a lo largo de la historia distintas formas de gobierno, pasando por monarquías, autocracias, dictaduras civiles, dictaduras militares, democracias modernas, democracias liberales, entre otros, hasta poder llegar a lo que, el día de hoy, es el Estado Constitucional de Derecho. Casi todos los países han optado por ser democráticos con una Constitución como carta fundamental y de mayor jerarquía, la cual contiene, por un lado, los principios básicos del sistema político y los deberes y derechos de la ciudadanía (parte dogmática); y, por otro lado, los mecanismos o lineamientos para delimitar la estructura constitucional y determinar la organización de los Poderes del Estado(1) en cuestión (parte orgánica).

La democracia constitucional contemporánea es, pues, una de las formas de gobierno ideal y que tiene por objetivo alcanzar a la mayoría de países. Los ataques a la democracia a través de golpes de Estado o utilización militar, sin elecciones de autoridades (o pasando por encima de ellas), tiene una mirada de desaprobación por los demás países y de sanción por parte de las cortes internacionales. Tiene, por el contrario, una perspectiva optimista el hecho de que las constituciones recojan y tutelen cada vez más derechos constitucionales, y que se siga un sistema electoral democrático.

No obstante, si bien ahora tenemos Estados democráticos más fuertes, con mecanismos constitucionales más sólidos y cuyas elecciones son regulares y competitivas a como antes lo era, ha sido inevitable que las dictaduras latinoamericanas de la segunda mitad del siglo XX influenciaran en la creación del diseño de los textos constitucionales que hoy en día tenemos (Gargarella, 2013, p. 148). Eso quiere decir que existe, lamentablemente, un fuerte impacto de las dictaduras anteriores en este constitucionalismo contemporáneo. Uno de los ejemplos es Brasil, país el cual reformó la Constitución de 1946 por la Constitución Democrática de 1988; no obstante, si bien pudo modificar la organización de los derechos fundamentales, no alteró sustancialmente la organización de poderes que ya había dejado puesta la dictadura militar por la que pasaron en 1967 (Gargarella, 2013, p. 150).

Al conocer que nos encontramos ante el "fenómeno de la dependencia institucional con el pasado dictatorial" (Queiroz \& Robl, 2019, p. 82) ${ }^{(2)}$, surge la necesidad de cuestionar y analizar si realmente estamos ante este nuevo constitucionalismo democrático o si, por desgracia, tenemos un cuerpo normativo constitucional que amenaza con reproducir conductas antidemocráticas de las dictaduras pasadas, o peor aún, que ya las ha o está repercutiendo.

\section{Concepciones iniciales sobre el Constitucionalismo abusivo}

Hoy en día, podemos observar un fenómeno que ocurre en Estados cuyas formas de gobiernos son aparentemente democráticas

(1) Si bien existe discusión en la doctrina sobre el significado del término "Poderes del Estado", se ha recurrido de forma técnica a este término para referir, a lo largo del texto, al Poder Legislativo, Poder Ejecutivo y, en su defecto, al Poder Judicial. Asimismo, se hace empleo del término "organismos" con la misma finalidad.

(2) Traducción propia del portugués al español. 
Constitucionalismo abusivo en el Perú: Un análisis a la vacancia presidencial por incapacidad moral y los hechos posteriores al 9 de noviembre de 2020

Abusive Constitutionalism in Peru: An analysis of presidential vacancy for moral incapacity and the events after November 9, 2020

y constitucionales. Aquellos Estados de Derecho terminan utilizando mecanismos o instrumentos constitucionales permitidos para debilitar la democracia y el control político, apareciendo así nuevas formas de dictadura en el siglo XXI. A este fenómeno se le denomina Constitucionalismo abusivo, figura nombrada y estudiada por David Landau, quien lo define de la siguiente manera: "el Constitucionalismo abusivo implica el uso de los mecanismos de cambio constitucional (enmiendas constitucionales y la reforma a una nueva constitución) para socavar la democracia" (2013, p. 191) ${ }^{(3)}$.

Las enmiendas constitucionales son mecanismos permitidos, pero que la mayoría de las veces han sido utilizados para fines personales e inconstitucionales:

(...) frecuentemente se aprueban enmiendas que siguen procedimientos democráticos formales para la enmienda constitucional, pero que están encaminadas a lograr objetivos constitucionales antidemocráticos o 'abusivos', por ejemplo, para ayudar a presidentes poderosos a que extiendan su mandato, para quitar controles parlamentarios (...) y para constreñir o suspender protecciones básicas de derechos humanos (Dixon \& Landau, 2015, p. 191).

Es así como, a pesar de que se sigue y respeta las vías constitucionales para realizar una enmienda a la constitución, este mecanismo termina deviniendo en la aparición de gobiernos "semiautoritarios" o "semiautorizados" que permiten que una sola persona concentre y se mantenga en el poder.

Las enmiendas a la constitución, o el cambio total por una nueva, son riesgosas debido a que la persona en el poder, es decir, el presidente, tiende a utilizar este mecanismo para permanecer en el mandato (aprobando la reelección de su cargo, por ejemplo), y así restarle facultades a los demás Poderes del Estado, para aumentar sus facultades, para debilitar los órganos de control autónomos o, incluso, para aplazar, evitar o dirigir los procesos electorales. Scheppele utiliza el término "democraturas" para este tipo de gobiernos, en donde los líderes populares llegan al poder a través de las elecciones, pero utilizan los institutos constitucionales para quebrantar el balance de poderes y callar a los grupos de oposición, a través del uso de los medios de comunicación (2016, pp. 4-7).

Deseo rescatar lo analizado por Dixon, autora que sostiene que, para encubrir estas enmiendas inconstitucionales, se ofrece a la ciudadanía nuevos derechos constitucionales a cambio, de tal manera que se utilizan estos derechos como un incentivo o "soborno" que permite que la sociedad apoye el proceso de enmienda junto con el proceso que va a la par de este: la reforma constitucional antidemocrática (2018, p. 240). Normalmente las reformas de derechos van de la mano con cambios en la configuración de la constitución y la organización de los organismos constitucionalmente autónomos.

De esta manera, el Constitucionalismo abusivo viene a ser esta creación de nuevas formas de gobierno, nuevas dictaduras o autoritarismos "solapados", a la luz de la democracia contemporánea. Es la utilización de los mecanismos de reforma constitucional para fines inconstitucionales, buscando que una persona o grupo político permanezca en el poder de forma aparentemente constitucional. Estas "dictaduras democráticas" llegan al poder y permanecen en él sin golpes de Estado; por lo que, al no ser notoria, muchas veces no nos hemos dado cuenta de que nos encontramos viviendo un Constitucionalismo abusivo.

Uno de los ejemplos más notorios en América Latina es el caso de Hugo Chávez - Venezuela. Este país llevaba muchas décadas sosteniendo una democracia fuerte; no obstante, en 1998, Chávez fue elegido por voto popular, ganando las elecciones con el $56 \%$ de los votos. Una vez en el poder, y sabiendo que el Congreso estaba conformado en su mayoría por miembros de su oposición, Chávez decidió neutralizarlo a través de una nueva constitución. Como la Constitución de ese momento solo preveía una enmienda por parte del Congreso, entonces Chávez aludió que el poder constituyente era del pueblo, por lo que realizó un referéndum para las elecciones de una Asamblea Constituyente.

Aceptado el cambio de constitución, y debido a que el texto constitucional de ese momento no mencionaba nada sobre cómo debía darse la Asamblea Constituyente, Chávez determinó todas las reglas del proceso, eligiendo a los miembros que la conformarían. El elegir a los miembros que conformaron esta Asamblea, como era evidente, le resultó notoriamente favorable: la Asamblea propuso el cierre de varias instituciones, suspendió el Congreso, creo un Consejo que fiscalizaría al Poder Judicial, eliminó las figuras de algunos funcionarios públicos e, incluso, cerró la Corte Suprema. Si bien la Corte Suprema apeló estas

(3) Traducción propia del inglés al español. 
decisiones, no fue tomada en consideración debido a que "el pueblo era el que tenía el poder".

La nueva Constitución eliminó el periodo de cuatro años que duraba el mandato presidencial, y lo reemplazó por dos términos de seis años de duración cada uno. Es así como Chávez permaneció más de doce años en el poder, y pasó a ser uno de los presidentes más fuertes de América Latina. No solo realizó el cambio de constitución, sino que, durante el periodo que estuvo en el poder, realizó enmiendas constitucionales para aumentar su capacidad de control por sobre las demás instituciones ${ }^{(4)}$. Este es uno de los ejemplos más claros de Constitucionalismo abusivo tal y como lo plantea David Landau, que en los casos más extremos puede terminar, como hemos visto, convirtiendo una fuerte democracia en una dictadura de mediados del siglo XX, y darnos cuenta solo cuando ya llegamos a ese punto.

\section{Redefiniendo el concepto de Constitucionalismo abusivo}

En el apartado anterior he descrito las primeras concepciones sobre el Constitucionalismo abusivo que fueron dadas por David Landau y las cuales son utilizadas por la mayoría de la doctrina hoy en día. Sin perjuicio de ello, es necesario replantear y extrapolar los supuestos de Constitucionalismo abusivo hacia otras formas por las cuáles también se utilizan mecanismos o instrumentos constitucionales para fines inconstitucionales. Sostengo que se puede considerar como Constitucionalismo abusivo a la utilización de normas o vías constitucionales que tienen por finalidad debilitar los cimientos de la democracia, sin necesidad de recurrir únicamente a las enmiendas constitucionales o al cambio de constitución.

Como podemos notar, el concepto de democracia es clave aquí para determinar cuándo estamos frente a un Constitucionalismo abusivo y cuándo no. Si bien dicho concepto aún genera debate en la doctrina acerca de todo lo que puede implicar, podemos afirmar que lo que asegura una democracia es el "control sobre el ejercicio del poder político, [la] separación de poderes y [la] garantía de las diversas dimensiones de los derechos fundamentales" (Queiroz \& Robl, 2019, p. 85) ${ }^{(5)}$, es decir, no se garantiza una democracia únicamente con la existencia de elecciones periódicas o con el hecho de que un Estado tenga los tres poderes, sino con una correcta configuración de las instituciones que refuercen la voluntad del pueblo y cuyas autoridades se encuentren bajo un mecanismo de rendición de cuentas que permita el control político. De esta manera, podemos concluir que existen diferentes formas de socavar la democracia sin utilizar enmiendas constitucionales, como planteó en un principio Landau.

Cabe hacer énfasis en el hecho de que, si bien tiene ventajas el poder extender los supuestos del Constitucionalismo abusivo, también traería dificultades el extrapolarlo demasiado, de tal manera que generaría un entorpecimiento teórico. No toda violación a la constitución o deficiencia de un gobierno democrático en donde algún mecanismo constitucional tuvo cierta participación se configura automáticamente en Constitucionalismo abusivo. El hecho de utilizar esta terminología para calificar a toda democracia débil genera una confusión que impide que se le dé el remedio correcto al fenómeno que lo necesita, de tal manera de que podríamos estar tratando una enmienda constitucional incorrecta como Constitucionalismo abusivo, cuando realmente están en juego otras implicancias políticas e históricas del Estado en cuestión (González, 2017, p. 448) ${ }^{(6)}$.

Para que estemos frente un Constitucionalismo abusivo, entonces, debe existir un ataque a los cimientos de la democracia, distorsionándola o socavándola, a través de la limitación o abolición de los elementos antes mencionados que la aseguran: (i) control del poder político; (ii) quebrantamiento de la división de poderes; y (iii) debilitamiento de las garantías de derechos fundamentales. Es necesario, de esta manera, "reconocer la diferencia entre, por un lado, una simple violación de la Constitución o de simple inconstitucionalidad $y$, por otro, una ocasión en la que estas inconstitucionalidades son dañinas para la democracia constitucional de una manera más estructural y peligrosa para mantener las propias bases democráticas" (Queiroz \& Robl, 2019, p. 87)(7) [énfasis agregado].

(4) Si desea conocer con mayor profundidad el análisis de los hechos ocurridos en Venezuela, puede leer a Landau (2013), pp. 203207.

(5) Traducción propia del portugués al español.

(6) Traducción propia del inglés al español.

(7) Traducción propia del portugués al español. 
Constitucionalismo abusivo en el Perú: Un análisis a la vacancia presidencial por incapacidad moral y los hechos posteriores al 9 de noviembre de 2020

Abusive Constitutionalism in Peru: An analysis of presidential vacancy for moral incapacity and the events after November 9, 2020

Por esta razón, con todo lo argumentado anteriormente, estoy de acuerdo con la redefinición del Constitucionalismo abusivo (tomando en cuenta los límites de una desproporcionada extrapolación), a través de la existencia de dos tipos o expresiones en las que este se manifiesta.

\subsection{Constitucionalismo abusivo estructural}

Esta primera manifestación de Constitucionalismo abusivo es la que se planteó desde un inicio por David Landau, y la más conocida en la actualidad. Es aquella que ataca a la democracia (utilizando los mecanismos constitucionales "legales") directamente hacia la estructura organizacional del Estado, es decir, cambiando las normas constitucionales, a través de las enmiendas o de frente con la creación de un nuevo texto constitucional. Martins (2019) menciona que el Constitucionalismo abusivo tiene las siguientes características:

En primer lugar, implica el uso de métodos constitucionalmente permisibles para modificar una constitución; en segundo lugar, implica la adopción de enmiendas a la constitución existente; en tercer lugar, tomadas individualmente, las enmiendas pueden no ser incompatibles con el constitucionalismo normativo, pero finalmente, considerando conjuntamente, las enmiendas se vuelven constitucionales (p. 36) $)^{(8)}$.

Como se ha mencionado antes, estos ataques a la democracia son difíciles de percibir a primera vista, tal y como lo describe la "parábola del sapo escaldado"(9), la cual menciona que, si uno intenta colocar a un sapo dentro de una olla con agua hirviendo, observará como hará todo lo posible para evitar entrar y salir de ahí; sin embargo, si lo coloca en una olla con agua fría, él no reaccionará, por más de que el agua gradualmente se esté calentando hasta que se hierva. El sapo no sentirá el cambio, pero morirá de todas maneras. Utilizando esta parábola para explicar este fenómeno, "Ias mismas personas que reaccionarían contra la toma manera autoritaria y antidemocrática, puede no reaccionar a los cambios en el que llegan al mismo resultado: la destrucción de la democracia" (Martins, 2019, p. 37) $)^{(10)}$.

Este tipo de Constitucionalismo abusivo lo hemos podido ver muchas veces en distintos países de Latinoamérica. Tenemos a Venezuela, antes mencionado, con la creación de un nuevo texto constitucional y enmiendas a este para permitir la reelección, o a Brasil, que hace poco reemplazó su Constitución por una nueva. En Colombia, se permitió la reelección de Álvaro Uribe gracias a las reformas constitucionales que se dieron ${ }^{(11)}$. En Bolivia, de igual manera, la Corte Constitucional boliviana aceptó la solicitud impuesta por el partido del expresidente Evo
Morales (Movimiento por el Socialismo) para suspender artículos de la Constitución que impedían la reelección inmediata. Asimismo, recientemente, en 2017, el presidente Nicolás Maduro, luego de haber perdido la mayoría en el parlamento a su favor, convocó a Asamblea Constituyente para crear una nueva constitución.

Incluso, si bien esto no ha sido estudiado desde el punto de vista de este fenómeno como tal, podríamos analizar y cuestionar que el Perú, en el gobierno de Alberto Fujimori, pudo haber vivido un Constitucionalismo abusivo estructural, a través de la creación de una nueva Constitución que le permitía mantenerse en el poder y que persiguió fines personales y antidemocráticos, así como la utilización de su posición para disolver el Congreso al no tener una mayoría parlamentaria a su favor.

Con los ejemplos anteriormente explicados, se concluye que el Constitucionalismo abusivo estructural se lleva a cabo en aquellas democracias cuyos sistemas de gobiernos son presidencialistas o "hiperpresidencialistas", es decir, en aquellos sistemas de gobierno en donde el Jefe de Estado tiene muchísimas facultades y muy poco control por parte del parlamento. En el presidencialismo, como sabemos, existe una separación notoria entre el parlamento y el gobierno, siendo ambos elegidos por voto popular, y recogiendo las figuras de Jefe de Estado y Jefe de Gobierno en una sola persona: el presidente (Nohlen, 2011, p. 88).

A la figura presidencial se le otorga varias facultades y protecciones con respecto al parlamento, lo que normalmente genera tensión en situaciones de crisis. Asimismo, existen Estados que han Ilegado a tener un "hiperpresidencialismo", en el cual el presidente termina teniendo la potestad de controlar instituciones que, en principio, deberían ser autónomas, tiene injerencia en las elecciones y cambios de mandato,

(8) Traducción propia del portugués al español.

(9) Parábola de Peter M. Senge (2010), en su Best Seller "A Quinta Disciplina: Arte e Prática da Organização que Aprende".

(10) Traducción propia del portugués al español.

(11) Inclusive, a modo de detallar la realidad colombiana en particular, la Corte Constitucional Colombiana tuvo que impedir una segunda reelección de Álvaro Uribe, recurriendo a otra reforma constitucional a someterse a referéndum, lo que le permitió desautorizarlo para un tercer gobierno. 
concentra en él competencias que le pertenecen a otros organismos, entre otros.

Son por estas razones que se afirma que el presidencialismo es una amenaza constante a la democracia de los países; puesto que permite con facilidad que se dé un Constitucionalismo abusivo estructural, y "se ha sostenido, incluso, que el derrumbe de las democracias en los años de 1960 y 1970 tuvo su principal causa en el presidencialismo" (Nohlen, 2011, p. 89). Esto genera nuevamente una discusión que lleva muchos años ya, sobre lo peligroso que puede resultar el presidencialismo, y que, por el contrario, el parlamentarismo sería la opción que ofrece una mejor expectativa para preservar la democracia (Linz, 1991, p. 52).

En conclusión, con todo el análisis realizado, se sostiene que es mucho más frecuente que el Constitucionalismo abusivo se desarrolle en aquellos sistemas de gobiernos presidenciales, como lo ha venido haciendo, cuyos Jefes de Estado utilizan su poder para mantenerse en el mandato; por lo que, una de las posibles soluciones que funcionaría como antídoto para combatir este fenómeno y preservar la democracia, sería la implementación de un sistema de gobierno parlamentario en todos los Estados (Linz, 1991, p. 52).

\subsection{Constitucionalismo abusivo episódico}

Este es el segundo tipo o manifestación de Constitucionalismo abusivo, aquel que, como su nombre lo dice, se da forma episódica o irregular. El término fue acuñado por Queiroz \& Robl (2019), aunque no fue desarrollado a profundidad del todo. Dichos autores señalan que "el fenómeno del constitucionalismo abusivo puede utilizarse [también] para describir el uso de procedimientos, institutos y medidas específicas del derecho constitucional para socavar o restringir la democracia constitucional en general" $(2019, \text { p. } 86)^{(12)}$.

Esta nueva categoría se emplea como herramienta de interpretación que permite ampliar los supuestos del Constitucionalismo abusivo tradicional (o estructural), e incluye a la utilización de instrumentos, institutos, procedimientos o normas constitucionales específicas que terminan estando en desacuerdo con las directrices de la democracia constitucional. En este caso, como podemos ver, no estamos frente a cambios estructurales como las enmiendas constitucionales o los cambios de Constitución.

Este tipo de Constitucionalismo abusivo, a diferencia del tipo estructural, es más propenso a ocurrir ya no en sistemas de gobierno presidenciales, sino en los sistemas parlamentarios, o en aquellos sistemas en los que el Parlamento mantiene una serie de facultades fuertes, como figuras de suspensión o destitución presidencial, lo que significa que la pérdida de la mayoría parlamentaria en el Congreso equivale a la pérdida del cargo del Presidente, para lo cual se recurren normas o mecanismos constitucionales, pero inusuales. Por ejemplo, tenemos el caso de Venezuela con el expresidente Carlos Andrés Pérez, que fue destituido de su cargo en 1993 por juicio político; o el caso de Ecuador con el expresidente Jamil Mahuad en el 2000. En Perú, se destituyó al expresidente Alberto Fujimori por la causal de "incapacidad moral"; y en Ecuador, en el año 1997, utilizaron la causal de "incapacidad mental" para destituir al expresidente Abdalá Bucaram. Distintas figuras constitucionales que fueron utilizadas para lo mismo: impedir que el presidente pueda terminar su mandato presidencial.

Como se ha podido observar, el Constitucionalismo abusivo no solamente puede ocurrir en los sistemas de gobierno presidenciales, como algunos lo afirman, puesto que también el parlamento, sin necesidad de realizar enmiendas o nuevos textos constitucionales, puede utilizar su posición para destituir al presidente mediante las normas constitucionales que lo "legaliza". La herramienta constitucional mayormente utilizada en este tipo de Constitucionalismo abusivo es el impeachment o juicio político. Tenemos el ejemplo de Brasil, que, en el año 2016, mediante el impeachment presentado contra Dilma Rousseff, logró destituir a la expresidenta, alegando el incumplimiento de normas presupuestarias.

Tal y como lo señalan Queiroz y Robl (2019), el impeachment o juicio político es una figura constitucional útil para poder restringir y controlar el poder que tienen los presidentes; no obstante, "el uso repetido de este mecanismo extremo es muy perjudicial para la democracia constitucional" (p. 93), lo que termina convirtiéndose en un arma para el parlamento contra el Poder Ejecutivo. Esto desmiente que el parlamentarismo sea el "antídoto" o la respuesta para vencer el Constitucionalismo abusivo, como algunos argumentan, y que este fenómeno se puede dar incluso en las democracias más sólidas y fuertes, independientemente del sistema de gobierno que tengan.

(12) Traducción propia del portugués al español. 
Constitucionalismo abusivo en el Perú: Un análisis a la vacancia presidencial por incapacidad moral y los hechos posteriores al 9 de noviembre de 2020

Abusive Constitutionalism in Peru: An analysis of presidential vacancy for moral incapacity and the events after November 9, 2020

No obstante, es menester aclarar que no siempre que observemos un Constitucionalismo abusivo estructural significa que nos encontramos bajo un sistema de gobierno presidencialista, al igual que el Constitucionalismo abusivo episódico no solo puede encontrarse en un sistema de gobierno parlamentario. Ambas manifestaciones de Constitucionalismo abusivo pueden darse en cualquier tipo de sistema de gobierno, únicamente se menciona que existen sistemas de gobierno más propensos en caer en un tipo de Constitucionalismo abusivo que en el otro, ya sea por la estructura organizacional del Estado o las atribuciones que se les otorga a las distintas instituciones.

Se sostiene, entonces, dos manifestaciones de Constitucionalismo abusivo, ambas de forma sigilosa e inadvertida, pero que terminan atacando las bases de la democracia constitucional. Asimismo, el sistema de gobierno y las figuras institucionales que se le otorga a los Poderes del Estado cumple un rol fundamental que puede ayudar a identificar bajo qué tipo de Constitucionalismo abusivo estamos o podríamos caer en un futuro.

\section{Analizando al Perú: ¿presidencialismo o parlamentarismo?}

Adentrándonos más en nuestro ordenamiento jurídico y político en cuestión, junto con todo lo anteriormente argumentado sobre el Constitucionalismo abusivo, se vuelve necesario identificar antes que todo qué tipo de sistema de gobierno tiene el Perú, cuál es su organización y qué facultades le ha otorgado a cada uno de los Poderes del Estado. Sabiendo esto, podremos identificar las latentes amenazas o posibles vulneraciones por las que atraviesa nuestro sistema, lo que nos permitirá analizar, más adelante, los hechos ocurridos el 9 de noviembre de 2020.

El sistema parlamentario es aquel que concentra el poder político en el Parlamento, debido a que es el órgano escogido por voto popular y, por ende, legitimado democráticamente. Una vez elegido el Parlamento, se escoge al líder del partido político mayoritario para que sea quien se encargue del gobierno. Este líder escoge a su gabinete de ministros con los parlamentarios de su partido y, de esta manera, es nombrado el Jefe de Gobierno. De esta manera, si por alguna razón el partido pierde su mayoría en el Parlamento, el Jefe de Gobierno cambia a la otra persona líder del nuevo partido mayoritario. El Jefe de Estado es otra persona distinta (el monarca), el cual solo ejerce funciones protocolares, mas no gobierna.

El Parlamento tiene la facultad de pedirle cuentas a los ministros, incluso al Jefe de Gobierno. Por el otro lado, este se encuentra facultado para disolver el Parlamento y convocar a nuevas elecciones cuando se le niegue la confianza; no obstante, solo si el partido del Jefe de Gobierno sigue siendo mayoría, el líder seguirá en el gobierno, caso contrario, este deberá renunciar. Como se puede observar, la "censura a los ministros y derecho de disolución son, pues, dos instituciones típicas del parlamentarismo que permiten resolver situaciones de crisis política" (Wieland, 2020), son las ruedas que permiten que este sistema parlamentario funcione de forma correcta, y normalmente se evita un conflicto entre ambos organismos, puesto que la mayoría parlamentaria está con el Jefe de Gobierno.

El presidencialismo, por el otro lado, es aquel sistema de gobierno en donde el Jefe de Estado y el Jefe de Gobierno se reúnen en una sola persona. Teniendo como ejemplo puro a la experiencia estadounidense, el presidente aquí, al igual que el parlamento, es elegido por voto popular, gozando de legitimidad democrática también. El presidente, entonces, asume el gobierno y, con ello, la responsabilidad política de sus decisiones; de igual manera, es quien elige directamente a sus ministros, quienes responderán políticamente ante el presidente, y no ante el Parlamento, es decir, este último no puede censurarlos.

Si el Parlamento no tiene permitido censurar a los ministros, entonces aquí el presidente tampoco puede disolver el Parlamento. Tampoco tiene la facultad de plantear cuestiones de confianza sobre propuestas legislativas. El primer ministro no se convierte en el Jefe de Gobierno como el parlamentarismo, sino que viene a ser un ministro más elegido por el presidente, y quien ayudará para la conformación de todo el gabinete de ministros (Blancas, 1996, p. 87). Como se puede notar, aquí el Poder Legislativo y el Poder Ejecutivo están bien distinguidos y separados, pero eso no impide que deban trabajar coordinadamente, cuyos puntos de encuentro suelen estar establecidos en la Constitución.

Sin embargo, cabe preguntarnos entonces, ¿qué sistema de gobierno tiene

(13) Término utilizado por Hubert Wieland Conroy (2020).

(14) Este término es comúnmente utilizado, puede encontrarlo en Espinosa-Saldaña (2007) o Eguiguren (2007). 
nuestro país? Evidentemente, el Perú ha recogido varias figuras de ambos sistemas de gobierno, creando un híbrido. Escogió, en un principio, el sistema presidencialista, siguiendo como modelo a Estados Unidos; no obstante, ha incorporado a lo largo de los años distintos elementos del parlamentarismo, por lo que algunos lo llaman presidencialismo parlamentarizado ${ }^{(13)}$, presidencialismo latinoamericano ${ }^{(14)}$, o semi-parlamentario, designando así a un sistema que inicia como presidencialista, pero que ha agregado instituciones propias del parlamentarismo.

En efecto, aquí el presidente de la República es elegido mediante elecciones, reúne en él tanto las figuras de Jefe de Estado y Jefe de Gobierno, así como tiene la facultad de elegir y también remover a sus ministros. Una vez elegidos los ministros, se forma el Consejo de Ministros, el cual tiene su propio. Aquí podemos notar rasgos del parlamentarismo, pues también está esta figura de "gabinete"; sin embargo, el Presidente del Consejo de Ministros no es el Jefe de Gobierno, ni es elegido por el Parlamento, sino que puede ser removido por el Presidente en cualquier momento.

Asimismo, el Presidente del Consejo de Ministros, una vez elaborada la política general del gobierno, debe presentarse para solicitar la confianza al Congreso, quien puede otorgársela o negársela. Resulta poco eficiente que, luego de que dicha política haya sido respaldada por el pueblo, tenga que necesitar un nuevo respaldo por parte del Congreso, dando a relucir la poca compatibilidad de la "investidura" dentro de un sistema presidencialista. De igual manera, nos encontramos también con la figura de la censura de ministros por parte del Congreso; así como el mecanismo de disolución del Congreso, ambos elementos que sirven de contrapeso, pero que funcionan correctamente en un sistema parlamentario, no presidencialista.

La disolución del Congreso genera que el presidente convoque a elecciones nuevamente e instaure uno nuevo; no obstante, y a diferencia del parlamentarismo, el Presidente de la República no renuncia a su cargo si es que su partido no obtiene la mayoría, sino que se mantiene hasta finalizar su mandato. A todo esto, Blancas añade que, a pesar de que presentamos figuras del sistema parlamentario, el Perú sigue siendo presidencialista en gran parte, puesto que el Presidente de la República tiene muchísimas más facultades en comparación al Congreso (1996, p. 87-92).

Como hemos podido observar, existe una mezcla (desordenada, en cierta medida) de figuras constitucionales de ambos sistemas presidenciales, siendo estos en principio extremos opuestos. Esto lo que genera es que exista constantes tensiones fuertes entre el Poder Legislativo y el Poder Ejecutivo a lo largo de los años. El diseño constitucional que tiene nuestro país solo parece ser viable cuando el Presidente de la República tenga a la mayoría del Congreso a su favor, asegurándole el voto de confianza a todo su Consejo de Ministros. No obstante, este ideal no sucede tan seguido como quisiéramos. Aunque lo que se esperaría sería que, a pesar de que no se simpatice, puedan actuar de forma políticamente madura y en coordinación, al final nos encontramos en la situación de que ambos terminan teniendo herramientas constitucionales para atacar al otro cuando así lo requieran sus intereses.

Podríamos concluir este apartado afirmando que el Perú es altamente propenso a adolecer de un Constitucionalismo abusivo en sus dos modalidades por el sistema híbrido que tiene, el cual presenta tanto a un presidente fuerte con muchas facultades, asi como a un Congreso con los mecanismos constitucionales suficientes para destituirlo de su mandato. No solo eso, sino que cada sistema presidencial debe ser entendido no solo desde la teoría, sino considerando en cuenta también aspectos de la historia política y social por la que ha atravesado el país en cuestión. Tomando en cuenta eso, el Perú ha sido un país cuyos gobiernos han sido en su mayoría dictaduras civiles y militares, lo cual ha influenciado sin duda al cuerpo constitucional que tenemos el día de hoy; por lo que podemos afirmar que nuestro país está contantemente amenazado a caer en un gobierno autoritario nuevamente.

\section{La vacancia por "incapacidad moral"}

Nuestra Constitución de 1993 contempla los supuestos para vacar al presidente de su cargo. Cabe enfatizar que la vacancia presidencial no es una sanción, medio de control ni penalidad hacia el presidente (como sí lo sería el juicio político o la censura), sino que es una medida que se toma para evitar que el cargo presidencial se quede vacío por cualquiera de las causales expuestas en la norma, las cuales impiden que el presidente pueda seguir en el mandato.

Una de estas causales de vacancia es la incapacidad moral, que se encuentra en el artículo 113 inciso 2 de la Constitución: "La Presidencia de la República vaca por: (...) 2. Su permanente incapacidad moral o física, declarada por el Congreso". Esto ha generado mucho debate, tanto en el ámbito 
Constitucionalismo abusivo en el Perú: Un análisis a la vacancia presidencial por incapacidad moral y los hechos posteriores al 9 de noviembre de 2020

Abusive Constitutionalism in Peru: An analysis of presidential vacancy for moral incapacity and the events after November 9, 2020

constitucional como político, buscando poder delimitar o darle una correcta interpretación a esta causal, y que no sea utilizada de forma arbitraria por parte del Congreso.

Una primera interpretación dada por una parte de la doctrina es que la incapacidad moral hace referencia a la incapacidad mental o "psíquica" realmente, que, junto con la incapacidad física también mencionada, se entiende que podría incapacitar al presidente de continuar en el gobierno. Esta teoría se complementa junto con los siguientes dos detalles: “a) la calificación de permanente incapacidad, la cual solo tiene sentido si se está pensando en "moral" como sinónimo de "mental"; y, b) el hecho de que no se haya previsto en la Constitución la incapacidad psíquica o psicológica, lo cual tendría pleno sentido con el objetivo que busca la vacancia" (Cruces, 2018, p. 264).

Por otra parte, Eguiguren afirma con justa razón que "atribuir a la incapacidad moral un sentido distinto a la incapacidad mental conlleva inconsistencia técnica y riesgos políticos muy notorios, pues permite un juicio valorativo, subjetivo y político de la conducta presidencial o la posibilidad de una suerte de "censura" parlamentaria, que acarreen la destitución del Presidente" (2007, p. 4). Evidentemente, darle otra acepción al término "moral" podría significar que la vacancia estaría siendo utilizada como control político o sanción, desnaturalizando su finalidad.

Una segunda interpretación que sobresale en el debate es la interpretación histórica, es decir, observar cómo esta causal ha sido empleada en la práctica, para así determinar su verdadero significado. Al analizar las veces en las que se ha vacado a un presidente o se ha intentado hacerlo en nuestro país, podemos concluir que la incapacidad moral no ha sido entendida como incapacidad mental, sino como inconducta moral o actos "indignos" de un Presidente. Aquí, como lo señala Cruces, estaríamos ante una mutación constitucional, pero no del órgano jurisdiccional, sino del propio Congreso de la República (2018, p. 267).

Una tercera y más reciente interpretación que se plasma en el debate constitucional es la interpretación con base en la fórmula política de nuestro país. Como ya hemos definido anteriormente, nuestro sistema de gobierno es semiparlamentarista, es decir, nace siendo presidencial, pero ha ido adoptando instituciones del parlamentarismo. Conociendo nuestro sistema y las deficiencias que tiene, no es posible que la interpretación que se le debe dar a la incapacidad moral:

1) vaya en el sentido de un parlamentarismo, negando así la identidad propia del sistema que recae en la legitimidad propia de la figura presidencial; y 2) potencie en exceso al presidente, pues es justamente uno de sus rasgos el haber introducido matices al ejercicio de un poder desmedido por su parte (Cruces, 2018, p. 274).

En este sentido, García Chavarri (2008), uno de los que apoya esta interpretación, concluye que el ámbito de aplicación de la vacancia por incapacidad moral sería "aquellas conductas graves que, sin ser delitos ni infracciones de un juicio político, deterioren a tal magnitud la dignidad presidencial que hagan que no pueda ser posible que su titular se mantenga en su cargo" (p. 402). No obstante, si bien puede ser una interpretación más integral, considero que de igual manera no soluciona uno de los problemas más grandes que tiene esta figura: la arbitrariedad de su uso y el peligro de que pueda ser utilizado reiteradas veces.

Con todo lo mencionado anteriormente, hemos podido conocer diferentes posturas que existen en la doctrina con respecto al significado de la incapacidad moral; sin embargo, sigue sin haber alguna concordancia en el debate hasta el día de hoy, es por esto que, incluso, existen quienes proponen una reforma a este artículo para eliminarlo de la lista de causales. No obstante, si bien no existe un consenso total sobre lo que esta figura podría implicar, sí podemos establecer ciertos puntos básicos que no se deben poner en cuestión: (i) la vacancia no es una forma de control político o de sanción al Presidente, sino que únicamente vela por la protección de la continuidad de la función presidencial; (ii) la vacancia no se puede dar por criterios meramente subjetivos con una interpretación muy amplia, ya que abriría las puertas a su uso arbitrario; y (iii) el Congreso de la República no está facultado para derribar o destituir al Jefe de Gobierno cuando lo considere necesario, ya que no nos encontramos en un régimen parlamentario.

A continuación, entonces, analizaremos la última vacancia presidencial por incapacidad moral dada en el Perú, la cual fue dada contra el expresidente Martín Vizcarra. Asimismo, se determinará cuál fue la aparente interpretación que el Congreso le dio a esta causal y si su uso fue el correcto o si, por el contrario, fue empleado de forma arbitraria, como venimos advirtiendo.

\section{9 de noviembre de 2020: ¿Constitucionalismo abusivo?}

El 18 de septiembre de 2020 el Congreso realizó la votación para determinar si el 
entonces Martín Vizcarra sería vacado por incapacidad moral permanente, debido a los audios difundidos sobre el caso Richard Swing. Con 78 votos en contra, dicha vacancia no fue aprobada. No obstante, tan solo 52 días después, el 9 de noviembre, el Congreso vuelve a presentar nuevamente el pedido de vacancia del presidente por la causal de incapacidad moral permanente. A diferencia del 18 de septiembre, hubo 105 votos a favor de la vacancia, lo que destituyó esa misma noche a Martín Vizcarra de la silla presidencial.

El Presidente del Congreso de la República, Manuel Merino, quien fue el que dirigió todo este procedimiento, es nombrado Presidente de la República al día siguiente, lo que generó un desacuerdo por gran parte de la población, ya que no se estuvo de acuerdo con la vacancia de Martín Vizcarra. Esto generó que, para los siguientes días, muchísimas personas en diferentes partes del país salieran a marchar y protestar para que Merino se retire del poder, incluso estuvo presente la corriente que sostenía la necesidad de crear una nueva constitución.

Lo primero que debemos analizar aquí es la interpretación que el Congreso le dio a la incapacidad moral permanente para aplicarla hacia Martín Vizcarra. Esta, definitivamente, fue la de considerar lo "moral" como conducta "indigna" o "reprochable", y no como mental o psíquica. Como ya se mencionó anteriormente, esta es la interpretación más peligrosa que existe, pues la convierte en una causal muy abierta y subjetiva que depende de lo que en ese momento el Congreso considere como "indigno de un Presidente".

La razón para argumentar la incapacidad moral permanente fue debido a la existencia de investigaciones por presunta corrupción durante el mandato de Martín Vizcarra en Moquegua (presuntos pagos de 640 mil dólares por dos obras), ¿puede ser esto considerable como incapacidad moral? Si ya existían investigaciones en marcha, el Congreso entonces no debió interferir en la justicia, sino dejar que estas continuarán en curso. A esto debemos añadir que no se llevó a cabo un debido proceso, ya que la votación duró solo pocas horas, y el Congreso terminó siendo tanto juez como parte.

Podemos observar que la incapacidad moral fue utilizada sin respetar los tres puntos básicos que se mencionaron líneas arriba. En primer lugar, fue utilizada como una herramienta de control político, desnaturalizando el propósito de la figura de vacancia. El hecho de haber intentado dos vacancias hacia Vizcarra de forma tan seguida (sin contar los dos intentos de vacancia también realizados hacia Pedro Pablo Kuczynski) demuestra un enfrentamiento político entre ambos organismos, utilizando los mecanismos constitucionales como amenaza.

Es menester traer a colación el Caso Petro vs. Colombia, en el cual el Sr. Petro fue destituido de su cargo de alcalde por la Procuraduría, quien también asumió un rol de juez y parte. En este caso, "la Corte concluyó que dicha sanción constituyó una violación a los derechos políticos del señor Petro en los términos del artículo 23 de la Convención, porque no fue impuesta por un juez competente en un proceso penal, con arreglo a las garantías judiciales contempladas en el artículo 8 del mismo instrumento" (Corte Interamericana de Derechos Humanos, Sentencia N. C-406, 2020). De esta sentencia, queda claro que existen derechos políticos que deben ser respetados, y que no se puede destituir a un funcionario público de un cargo si no existe una sentencia firme por parte de un juez en un proceso penal que así lo exija. El Congreso de la República debió permitir que las investigaciones penales terminaran.

En segundo lugar, la vacancia se dio por medios muy subjetivos, por lo que terminó configurándose en una destitución arbitraria con una amplia interpretación de la causal. Por último, el Congreso terminó ejerciendo un poder como si estuviésemos en un sistema parlamentario puro, pues destituyó al Jefe de Gobierno con una causal, siendo juez y parte, en menos de 5 horas, solo porque así lo quiso. Si bien tenemos figuras del parlamentarismo, nuestro gobierno sigue siendo presidencial; eso significa que "el presidente es electo por un período fijo y solo puede ser destituido o declarado vacante por causales específicas, que tienen que ser probadas. Y eso no ocurrió en este caso" (Uprimny, 2020).

Habiendo reunido todas las piezas del rompecabezas, y después de analizar las implicancias de cada una de ellas, surge la pregunta que inspira esta investigación: ¿La vacancia presidencial por incapacidad moral del expresidente Martín Vizcarra configuró un Constitucionalismo abusivo en el Perú? La respuesta es afirmativa. Tal y como vimos anteriormente, el Perú presenció un Constitucionalismo abusivo episódico, aquel que no necesita de enmiendas o reformas constitucionales para atacar las bases de la democracia constitucional, sino que utilizó ciertas instituciones o mecanismos constitucionales para hacerlo. En otras palabras, el Congreso de la República utilizó el mecanismo constitucional de la vacancia presidencial por incapacidad moral para fines propios e inconstitucionales, que terminó por afectar la democracia.

Como se afirmó en apartados anteriores, entendemos por afectación o ataque a 
Constitucionalismo abusivo en el Perú: Un análisis a la vacancia presidencial por incapacidad moral y los hechos posteriores al 9 de noviembre de 2020

Abusive Constitutionalism in Peru: An analysis of presidential vacancy for moral incapacity and the events after November 9, 2020

la democracia, en primer lugar, al quebrantamiento o debilitamiento de la separación de poderes. Esto lo observamos definitivamente en los hechos del 9 de noviembre de 2020 y días posteriores: el Congreso de la República reunió en sí mismo al Poder Ejecutivo y al Poder Legislativo, fenómeno que es común en un gobierno parlamentario, en el que es el Parlamento quien al final concentra el poder de ambos organismos, pero esto no se vería nunca en un sistema presidencial o semiparlamentario. Evidentemente, nos encontramos no solo ante una grave afectación a la separación de poderes, sino también al sistema de gobierno mismo que tiene el Perú.

Como segunda premisa para saber si la democracia se ve vulnerada, está todo intento por contener el control político en una sola persona o institución por encima de los otros. Esto también se dio, puesto que prácticamente el Congreso de la República también gobernaba. Esto se demuestra con todos los proyectos de ley que se presentaron al segundo día de haber asumido la presidencia Manuel Merino. Por último, la democracia también se ve afectada cuando, para lograr lo cometido o como consecuencia de este, se han vulnerado los derechos fundamentales que establece la Constitución. En este caso, no se respetaron los derechos que conforman la tutela jurisdiccional efectiva por parte de Martín Vizcarra, así como también se vulneraron sus derechos políticos.

Luego de esto, es correcto afirmar que sí existió una vulneración a la democracia constitucional contemporánea de nuestro país. Sin una mirada crítica, todo pareciese indicar que la asunción de Manuel Merino fue un procedimiento constitucionalmente correcto; sin embargo, sustancialmente, este mecanismo fue utilizado para ir contra de todo lo que nuestro gobierno constitucional busca velar y proteger. Tal y como menciona Uprimny, "los grupos dominantes del Congreso peruano aprovecharon la ambigüedad de la figura de vacancia por incapacidad moral para tumbar a Vizcarra y tomarse la Presidencia" (2020).

Es por esta razón que generó confusión el considerar como antidemocrático la asunción al poder de Manuel Merino, pues formalmente la Constitución contemplaba que era lo que correspondía; sin embargo, la autora afirma que esta norma constitucional fue solo un mecanismo al cual recurrió el Congreso de la República como un intento para atrincherarse en el poder. Mecanismos inconstitucionales, uso de la ambigüedad que puedan tener algunos de ellos, todo para alcanzar lo que la misma norma intentaba prevenir: un debilitamiento de la figura presidencial. Presenciamos un Constitucionalismo abusivo en el Perú.

\section{Reflexiones finales}

El presente trabajo ha buscado ofrecer un análisis a la vacancia por incapacidad moral que se dio en el Perú el 9 de noviembre de 2020. Para esto, se ha determinado la existencia de dos tipos de manifestaciones de Constitucionalismo abusivo: el estructural y el episódico. Ambos pueden darse en cualquier sistema de gobierno; sin embargo, cada uno es más propenso a ocurrir en un sistema presidencial o parlamentario, respectivamente. Se señaló, luego, las implicancias de la vacancia presidencial por incapacidad moral, y todas las complicaciones que esta tiene al ser un término que viene siendo utilizado con una interpretación amplia y arbitraria, lo que se complica aún más por el sistema de gobierno híbrido que tiene el Perú, el cual presenta tanto figuras del presidencialismo como del parlamentarismo, que mantiene en constante tensión a los Poderes Legislativo y Ejecutivo.

Es así, que el trabajo demuestra que el Perú vivió un Constitucionalismo abusivo episódico al destituir a Martín Vizcarra del gobierno usando la figura de vacancia presidencial por incapacidad moral. Estos actos fueron formalmente correctos, pero terminaron afectando la separación de poderes y concentró el poder político en el Poder Legislativo, lo que significó un ataque y debilitamiento de la democracia. Por lo tanto, la utilización de este mecanismo constitucional (vacancia presidencial) para lograr fines anticonstitucionales que amenazaron la democracia es lo que nos permite afirmar finalmente que hubo un Constitucionalismo abusivo en el Perú.

El 15 de noviembre de 2020, luego de las constantes marchas por parte del pueblo peruano, Manuel Merino renunció al cargo presidencial. Esto demuestra que una considerable parte de la población fue crítica y pudo percibir que, a pesar de que los mecanismos utilizados eran los establecidos por nuestra Constitución, había algo que no cuadraba del todo, había algo que nos hacía sentir que nuestra democracia se había visto vulnerada. Ahora que se plantea nuevamente un cambio de Constitución, invito a los lectores a que tengamos la misma mirada crítica y reflexiva, recordemos que aún estamos influenciados por las dictaduras que nos precedieron. No permitamos nuevamente un Constitucionalismo abusivo estructural o episódico en nuestro país. 


\section{Referencias bibliográficas}

Blancas, C. (1996). El Poder Ejecutivo presidencial. Pensamiento Constitucional, 3(3), 85-102. http://revistas.pucp.edu.pe/index.php/ pensamientoconstitucional/article/view/3342

Corte Interamericana de Derechos Humanos. (2020, 8 de julio). Sentencia Serie C N ${ }^{\circ} 406$ (Caso Petro Urrego vs. Colombia). https://www.corteidh. or.cr/docs/casos/articulos/seriec_406_esp.pdf

Cruces, A. M. (2018). La interpretación constitucional de la vacancia del Presidente de la República por incapacidad moral. https://www. academia.edu/40129418/La_interpretación_ constitucional_de_la_vacancia_del_Presidente_ de_la_República_por_incapacidad_moral

Dixon, R. (2018). Los Derechos Constitucionales como Sobornos. Revista Derecho \& Sociedad, 51, 233-263. http://revistas.pucp.edu.pe/index.php/ derechoysociedad/article/view/20871

Dixon, R. \& Landau, D. (2015). Transnational constitutionalism and a limited doctrine of unconstitutional constitutional amendment. International Journal of Constitutional Law, 13(3), 606-638. https://doi.org/10.1093/icon/mov039

Eguiguren, F. (2007). La responsabilidad del Presidente de la República. Hacia una reforma constitucional. Portal de Asuntos Públicos de la PUCP. http://repositorio.pucp.edu.pe/index// handle/123456789/11971

García, M. (2008). Acusación constitucional, antejuicio y juicio político. Desarrollo teórico y tratamiento jurisprudencial. Repositorio Institucional de la PUCP. http:// repositorio.pucp.edu.pe/index/handle/123456789/39771

Gargarella, R. (2013). Latin American Constitutionalism, 1910-2010. The Engine Room of the Constitution. Oxford University Press.

González-Jácome, J. (2017). From abusive constitutionalism to a multilayered understanding of constitutionalism: Lessons from Latin America. International Journal of Constitutional Law, 15(2), 447-468. https://doi.org/10.1093/icon/mox017

Landau, D. (2013). Abusive Constitutionalism. 47 UC Davis law Review, 47, 189-260. https://ssrn.com/abstract $=2244629$

Linz, J. (1990). The Perils of Presidentialism. Journal of Democracy, 1(1), 51-69. https://doi.org/10.1353/jod.1990.0011

Martins, F. (2019). Constitucionalismo abusivo: realidade, perspectivas e propostas para uma limitacao. CATÓLICA LAWREVIEW, 3(1), 29-41.

Nohlen, D. (2015). El Presidencialismo: Análisis y diseños institucionales en su contexto. Revista de Derecho Público, 74, 87-111. https://doi. org/10.5354/0719-5249.2015.37537

Queiroz, E. \& Barboza, I. (2018). Constitucionalismo abusivo. Fundamentos Teóricos e Análise da sua Utilização no Brasil Contemporâneo. Revista Brasileira de Direitos Fundamentais \& Justica, 12(39), 79-97. https://doi.org/10.30899/dfj.v12i39.641

Scheppele, K. (2016). Worst Practices and the Transnational Legal Order (Or How to Build a Constitutional "Democratorship" in Plain Sight). Background paper: Wright Lecture. University of Toronto. https:// perma.cc/Q266-MJEK

Uprimny, R. (2020, 17 de noviembre). La crisis peruana y el constitucionalismo abusivo. Dejusticia. https://www.dejusticia.org/ column/la-crisis-peruana-y-el-constitucionalismo-abusivo/

Wieland, H. (2020, 8 de agosto). Parlamentarismo vs. Presidencialismo en el Perú. La Mula. https://plumainquieta.lamula.pe/2020/08/08/ parlamentarismo-vs-presidencialismo-en-el-peru/hubert/ 